\title{
Research on Innovation of Logistics Terminal Distribution Service Mode
}

\author{
Jingjing Kong, Youxia Zhao, Fan Wang, Qianyu Xiang \\ Anhui University of Finance and Economics, Bengbu, China \\ Email: 1481246199@qq.com,3214362280@qq.com,2329914293@qq.com,1753796942@qq.com
}

How to cite this paper: Kong, J.J., Zhao, Y.X., Wang, F. and Xiang, Q.Y. (2021) Research on Innovation of Logistics Terminal Distribution Service Mode. Open Access Library Journal, 8: e8242.

https://doi.org/10.4236/oalib.1108242

Received: November 30, 2021

Accepted: December 14, 2021

Published: December 17, 2021

Copyright $\odot 2021$ by author(s) and Open Access Library Inc.

This work is licensed under the Creative Commons Attribution International License (CC BY 4.0).

http://creativecommons.org/licenses/by/4.0/ (c) (i) Open Access

\begin{abstract}
At present, China's e-commerce logistics terminal distribution adopts courier delivery, post access express, agent access express, etc., which causes many problems in logistics terminal industry, such as disorder, inefficiency, waste of cost, lack of standards, and leakage of users' personal information, which need to be solved urgently. This paper will introduce an intelligent express access integrated machine which combines rotary intelligent access system, stacker and self-service express electronic system. Among them, the rotary intelligent access system gives instructions to the stacker according to the information obtained from the self-service express electronic system, and the stacker searches for the corresponding express according to the instructions, the two cooperate with each other to form an integration of intelligent systems. The whole process operation changes the original messy manual operation mode, making it more intelligent and orderly. The development of this product integrates, unifies and standardizes the warehousing mode of e-commerce logistics, builds and strengthens the logistics infrastructure, meets the needs of the development of logistics industry, saves manpower, material resources and financial resources, and provides low-cost, high-quality, high-efficiency and private services for the vast number of users.
\end{abstract}

\section{Subject Areas}

Logistics and Engineering

\section{Keywords}

Access Integration, Intelligence, Security, Patterns of Warehousing Logistics

\section{Introduction}

The development popularization and application of modern techniques, com- 
puters and electronic communication networks symbolize the arrival of the electronic age, and great changes have taken place in human life. Online shopping has become a new way of shopping and brought along the development of logistics industry. Although some Chinese logistics enterprises have introduced high-tech working methods in some aspects, the distribution of logistics terminals still stays in the manual operation stage, which has become a bottleneck that restricts the development of e-commerce logistics.

\subsection{The Demands of Users}

\subsubsection{Residents}

Because of the COVID-19 epidemic, users pay more attention to personal health problems. When people are looking for their own packages, may pick up germs indirectly. Furthermore, some express stations need users to find express delivery packages by themselves, and they can't get the position quickly, so it is a waste of time.

\subsubsection{College Students}

There are many express stations in university, which are scattered and an integrated center of express services network has not formed yet. Moreover, the area is generally small, once the pick-up peak is met and the station is full, a series of unsafe events will occur, such as carrying express delivery secretly and causing stampede accident. There is even an unhealthy phenomenon that somebody falsely claims the package as his own, which is a kind of loss for both students and agents [1].

\subsection{The Demands of Market}

The development of express delivery industry is influenced by the delivery service quality of express terminal. There are many problems in this industry, such as low information utilization rate, low controllability and low flexibility. At present, Chinese terminal distribution is roughly divided into the following types: home delivery mode, intelligent self-lifting cabinet mode and manual self-lifting point mode. The advantages and disadvantages of these three modes are analyzed as follows [2] [3].

\subsubsection{Home Delivery Mode}

This mode could take a considerable amount of time to complete. According to statistics, it takes 5 hours to send the packages from the terminals satation to customer, which accounts $45 \%$ of the total express delivery time, however, the delivery distance is less than $5 \%$ of the total delivery distance. For courier services companies, the delivery objects are scattered, and the problems of not receiving goods in time and safety are often encountered. Customers are unwilling to place packages in the guard room, which leads to the courier's negative attitudes because of long dead time. Even the courier has to deliver repeatedly, and the delivery costs are also increased. In addition, from the security point of view, 
home delivery service is an invasion of privacy, and it is quite common for some lawless people to pretend to be couriers and invade users. There are even phenomena of stealing packages, the packages may be lost, because the express car is unattended when the courier goes upstairs to deliver. However, home delivery service still has its own advantages, it allows customers to inspect goods face to face, identify whether there is any damage in transit, and receive goods after confirmation. Home delivery service can give the users the best experience especially for some special large packages or some fresh goods that need refrigeration.

\subsubsection{Intelligent Self-Lifting Cabinet Mode and Manual Self-Lifting Point Mode}

These two modes have obvious advantages in saving courier's time, which not only reduces the communication part with users, but also realizes the customer's demand for time freedom, thus avoiding the waste of time for both sides, reducing the cost and improving the efficiency of logistics distribution [4]. However, the intelligent self-lifting cabinet is limited by the size of the cabinet, which is not suitable for large items. Although there are UnionPay charging terminals to collect money, it is too complicated for the elderly or those who are unfamiliar with intelligent self-service machines. And there is a great demand for labor at manual pick-up points, and the possibility of mistakes may exist.

This article gets the following conclusions through the comparative analysis of three distribution modes: home delivery service, intelligent self-lifting cabinet and manual self-lifting point: although the three modes have their own advantages, due to the high requirements of modern society on time planning cost, urban management, user commuting, information protection and other aspects. This paper will introduce a self-service express machine to meet the above needs, and cooperate with home delivery service as a supplement to meet the needs of users and logistics enterprises.

\subsection{What We Want to Solve-Technological Innovation}

\subsubsection{System Integration}

Intelligent combination of rotary intelligent access system, stacker and self-service delivery electronic system. Rotary intelligent access system gives instructions to the stacker according to the information obtained from the self-service delivery electronic system. The stacker searches for the corresponding express according to the instructions, and the two cooperate with each other to form an integration of intelligent systems. The whole process operation changes the original messy manual operation mode, making it more intelligent and orderly.

\subsubsection{Security}

The two-dimensional code system of user information is used, and the two-dimensional code on the packages is designed to keep the sender and recipient's information secret. Only the personnel related to express can scan the QR code to display the information of the packages. The information covered by the 
QR code includes the name, telephone number, address and object information of the sender and the recipient. In addition, those unhealthy phenomena such as helping others to pick up the packages or falsely claiming the packages, will not happen, which ensures the safety of packages [5].

\subsubsection{Convenience}

On the one hand, the independent express access machine developed by our team is convenient for users' lives, and can realize the liberalization of access express delivery, On the other hand, it is more orderly to mobilize the courier of the courier company, so the manpower and cost can be saved.

\section{Introduction of Product Operation}

\subsection{Rotary Stacker}

Rotary stacker is composed of vertical high-speed stacker (as shown in Figure 1) and rotary automatic intelligent access system. The main working principle of stacking crane is to operate inside the warehouse, take out the goods on the shelf and deliver them to the transfer port, or deliver the goods at the transfer port to the corresponding cargo compartment on the shelf. Rotary intelligent access system is a new generation of goods-to-people access equipment integrating warehouse and sorting. It takes the rotating shelf as the carrier, and the execution system automatically judges whether to rotate forward or backward after receiving the instruction from the control system, so that the rotation stroke is the shortest, thereby realizing the multiplication of the optimal efficiency of goods storage and retrieval, and solving the problems of warehouse intensive storage, storage, access and sorting of scattered goods for customers [6].

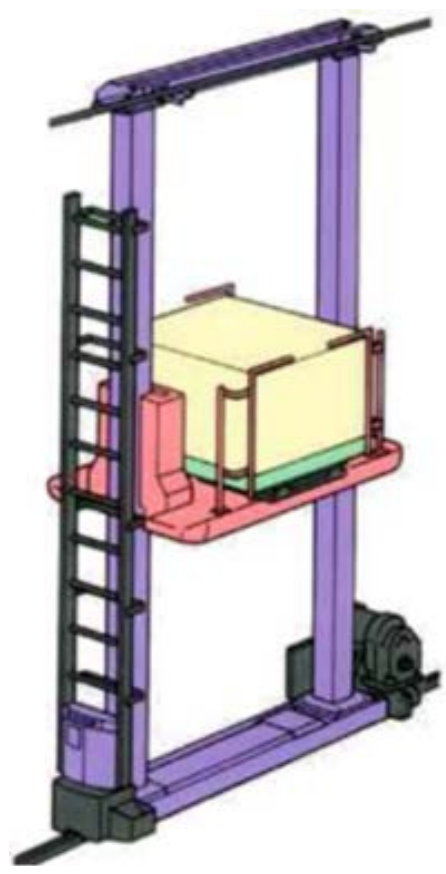

Figure 1. Vertical high-speed stacker. 


\subsection{Specific Operation Process}

\section{1) Courier's perspective}

The operations that the courier places the packages are as follows: First, scan the QR code of the back door of the courier cabinet, enter the mini program, and select "put in the package" in the "employee entrance"; Then, the courier puts the pacel one by one, and the pacel starts to operate through the conveyor belt, conveyor belt and vertical high-speed stacker, and puts the pacel in a suitable position; Finally, the courier selects "Update Logistics Information" on the applet to update the logistics information, and automatically sends the information to the recipient. The courier takes out the courier operation that the customer needs to mail, and carries out the reverse operations.

\section{2) Customer perspective}

Sender: First, select "Sender" on the front screen of the courier cabinet, and put the packaged pacel into the "Sender" for weighing and item inspection; Secondly, after the express inspection is qualified, the sender enters personal information and sends information on the screen, verifies the ID card at the bottom of the screen, confirms the information, confirms to print the QR code, and pastes the QR code to the express delivery; Finally, put the package in the "sending port" again, click "confirm sending", and pay the total freight.

Pick-up: First, select "Pick-up" on the front screen of the express cabinet, click "Customer Portal" in the applet, select "Pick-up QR code", and scan it at the bottom of the screen; Secondly, after scanning the QR code, confirm the courier information displayed on the screen, click "Confirm pickup", and take out the parcel from the "pickup port"; Finally, click "Complete Pick-up" to complete pick-up.

\section{3) Machine internal perspective}

The machine is stored in the express delivery operation: after the express delivery is placed on the conveyor belt, it is disinfected by ultraviolet rays, and then the QR code on the express delivery is scanned to enter the information; Then, according to the intelligent access system, the corresponding placement position is obtained through analysis, and the stacker places the express delivery at this position to complete the relevant operations. The machine can take express related operations and vice versa.

\section{PEST Analysis}

PEST analysis refers to the analysis of macro environment, $\mathrm{P}$ is Politics, $\mathrm{E}$ is Economy, $\mathrm{S}$ is Society, $\mathrm{T}$ is Technology. In terms of economy, the main contents include economic development level, scale, growth rate, government revenue and expenditure, inflation rate, etc. In terms of politics, there are political systems, government policies, national industrial policies, relevant laws and regulations, etc. Social aspects include population, values, moral level, etc. In terms of technology, there are breakthroughs in high and new technology, process technology and basic research. 


\subsection{P-Policy}

The $13^{\text {th }}$ Five-Year Plan for the Development of Smart Express Cabinet Industry issued by the central government clearly requires that the smart express cabinet industry should grow by $30 \%$ by 2020 , and has issued relevant policies to improve the industry penetration rate. In 2019, the smart express cabinet industry will become a policy dividend market. Relevant reports pointed out that the intelligent express cabinet industry will help improve people's quality of life.

\subsection{E-Economic}

With the development of the logistics distribution system and the number of online shopping users increasing, it continues to grow rapidly. In 2019, the number of online retail sales goods in China increased by $19.5 \%$ compared with last year, and the growth rate was 11.5 percentage points faster than the total retail sales of social consumer goods, accounting for $20.7 \%$ of the total retail sales of social consumer goods, 2.3 percentage points higher than last year. The State Post Bureau estimates that in 2019, the express delivery business volume and business income will reach 63 billion pieces and 745 billion pieces respectively, with an increase of $24 \%$ and $23 \%$ respectively. It is estimated that online retail sales of physical goods contribute more than $45 \%$ to the growth of total retail sales of social consumer goods.

\subsection{S-Society}

1) For customers: Full-time self-service, pick up packages at any time, and have a high degree of freedom in time; Simple operation and convenient access; Effectively protect residents' privacy and improve their quality of life.

2) For couriers: Reduce unnecessary communications with customers; Delivery of express cabinets saves delivery time; Centralized delivery, could reduce secondary delivery.

3) For residential property management: unified management is more standardized, which can reduce disputes between owners; The accumulation reducing could improve service quality; and the intelligent level of the community.

\subsection{T-Technical}

The delivery box terminal system mainly adopts two core technologies, namely cloud computing and Internet of Things, and front-end express access and back-end data processing are the two main parts. The whole intelligent express delivery system mainly relies on express intelligent cabinet terminal and PC server.

\section{Project Summary}

In today's world of technicalization and informationization, an efficient and convenient "contactless service" such as "intelligent express access integrated machine" will be the main trend of the development of logistics distribution in- 
dustry. Especially under the influence of the COVID-19 epidemic, the traditional logistics and distribution industry is facing a huge risk of cross-infection caused by the contact of mobile personnel. Express delivery personnel inevitably come into contact with a large number of people from all walks of life every day, and while cooperating with strict inspection measures for prevention and control of COVID-19 epidemic, the efficiency of express delivery and mailing business is greatly reduced. The intelligent express access integrated machine project perfectly solves these two problems. It has greatly increased the efficiency of logistics distribution business while effectively preventing and controlling the epidemic and reducing personnel contact. This kind of "contactless service" has won popular support. For the intelligent express access integrated machine, it is efficient and convenient, and effectively avoids the risk of epidemic infection.

In today's era of stock game between e-commerce and logistics industry, its competition will become more and more intense. The rotary stacker adopted in this project realizes the optimal efficiency of storing and picking goods, and solves the problems of intensive storage in warehouses, storage, access and picking of scattered goods for customers. In the absence of market-related technologies, this project can monopolize this new type of sending and picking mode. Starting from the profit model, consumers enjoy a kind of "value-added service" compared with the self-concept of express delivery cabinet, In the era of stock game, we should pay attention to transparency and legitimacy for service. Only when it is legal and reasonable can it be recognized by the majority of users and achieve lasting and long-term development in the whole Internet economy. Of course, a third-party terminal logistics service platform like Cainiao Post has been accepted by some people, but its own rental expenses and staff salaries are higher than those of express access integrated machines. Although there is no charge at present, the loss-making service cannot be sustained for a long time.

The "last few hundred meters" of the package is extremely small in the whole transportation, but it is the segment with the strongest experience for consumers and logistics users. This is an important guarantee for the diversification of e-commerce business, and restricts the future development direction of e-commerce. It is also a key factor that truly reflects the advantages of e-commerce. The intelligent express access integrated machine developed by our team gives users a better sense of use in the "last few hundred meters", and has obvious advantages in the highly competitive logistics distribution mode. When customers get convenience from the project, their usage habits will be enhanced with the convenience brought by the intelligent express access integrated machine. Add the idea of intelligent express access integrated machine to the business model of the enterprise to manage the terminal logistics [7] [8]. After optimizing the logistics link and cost structure, the relationship among enterprise cost, terminal logistics distribution efficiency and customer satisfaction is comprehensively considered, and advanced technologies such as artificial intelligence and Internet of Things are used to promote industrial progress. 


\section{Fund Project}

This paper belongs to the 2020's national college students' innovation and entrepreneurship training project "Research on the innovation of e-commerce logistics terminal distribution mode based on intelligent express access integrated machine" (project number: 202010378020) results.

\section{Conflicts of Interest}

The authors declare no conflicts of interest.

\section{References}

[1] Shen, P., Luo, J., Li, Y., Li, B. and Ling, Z. (2018) Discussion on the Last Mile of Campus Express Delivery-Taking Pingxiang University as an Example. Logistics Engineering and Management, 40, 116-118.

[2] Liu, B. (2017) Development Status and Countermeasures of Urban Express Terminal Distribution Mode. Science and Technology Economic Guide, No. 16, 195-196.

[3] Guo, Z. (2017) Research on the Development Problems and Countermeasures of China's Third Party Logistics. Procedures of 2017 6th International Conference on Applied Social Science (ICASS 2017), 98, 201-205.

[4] NGO nhu Tai (Yue Caihou) (2018) Bottleneck analysis and Countermeasures of logistics services in Vietnam. Dalian Maritime University, Dalian.

[5] Yao, S. (2018) Express Delivery System Based on QR Code and Android Platform. Xi'an University of Science and Technology, Xi'an.

[6] Zhou, B. (2018) Innovative Research on Logistics Terminal Distribution Mode Based on Internet Technology. Intelligent Computer and Application, 8, 92-95+102.

[7] Lin, L. (2019) Thoughts on E-Commerce Logistics Terminal Distribution. Marketing, No. 52, 234+252.

[8] Huang, H. (2020) Research on Sustainable Development of Reasonable Profit Model of Express Cabinet. China Business Theory, No. 24, 19-20. 